\title{
ON-BOARD AIRCRAFT ULTRASONIC BIRD REPELLER
}

\author{
M Surya, Namita L Rao, Pratham Kumar D \\ Mr. Santosh Kumar B.R \\ Associate Professor \\ Department of Electronics and Communication \\ Kammavari Sangham Institute of Technology \\ No.14, Raghuvanahalli, Kanakapura Road \\ Bengaluru-560109, India
}

\begin{abstract}
With the growing technological advancements a really prevailed downside within the aeronautical institutes is the Bird Strike, that has to be handled in a sophisticated manner. A Bird Strike is strictly outlined as a collision between a bird associated with an aircraft that is on the wing or on a Take-Off or Landing roll and also the term is usually swollen to hide alternative life Strikes with haywire or ground animals [12]. Bird Strikes typically occur throughout the Take-Off or Landing sections thanks to the lower altitudes of the aircrafts throughout that phase. Indian airports have recorded a gradual increase in range of bird hits and craft run-ins with stray animals over a minimum of the past 5 years, in step with official information, illustrating the potential safety risks and losses the aviation business confronts from such accidents because the fleet of planes operated by domestic airlines expands apace [11]. in step with board of directors General of Civil Aviation (DGCA) an information was provided in response to a Right to data (RTI) application filed by geographic area Times that contained the amount of Bird Strikes [11]. In 2014, the amount of bird hits and animal strikes was 719, in 2015 it absolutely was 764, in 2016 with a count of 839, in 2017 a spike of 1125 was noticed and in 2018, the count was 1244 [11]. The current techniques showing smart results against Bird Strikes aren't effective enough to beat this downside. therefore this paper produces a plan with usage of sound to forestall Bird Strike that disturbs the birds and causes them to
\end{abstract} maneuver away.

To overcome this downside, we tend to square measure reaching to use "Ultrasonic radiation" which will be radiated throughout the flight takeoff and landing that disturbs the birds (without harming them) and additionally not moving the pilots throughout their
Keywords: Bird Strike, Flight Take-Off and Landing, supersonic radiation, craft safety

\section{INTRODUCTION}

Bird strikes happen most often during TakeOff or Landing, or during low altitude flight. The majority of bird collisions occur near or at airports $(90 \%$, according to the International Civil Aviation Organization (ICAO) ) during Take-Off, Landing and associated phases [18]. According to the FAA (Federal Aviation Administration) and wildlife hazard management manual for 2005 , less than $8 \%$ of strikes occur above 900 meter (3,000 feet) and $61 \%$ occur at less than 30 meters (98 feet) [18]. Noticing the facts of this survey the Bird Strike prevention should be concentrated at lower altitude regions. Before discussing about the prevention techniques, one must know the importance of building a device for prevention.

The aircrafts undergo a huge impact due to the Bird Strike. The collision along with damaging the parts of the aircraft also disturbs the pilot which hence causes hindrance in having a safe flight. The upcoming section describes the various hazards caused to the aircrafts when it undergoes a Bird Strike.

\section{Impacts of Bird Strike}

The nature of aircraft damage from Bird Strikes, is significant enough to create a high risk to continued safe flight, and along with this the impact of damage also depends on size of aircraft [11]. Small, propeller-driven aircraft are most likely to experience the hazardous effects of strikes as structural damage, such as the penetration of flight deck windscreens or damage to control surfaces or the empennage [12]. Larger jet-engine aircraft are most likely to experience the hazardous effects of strikes as the consequences of engine ingestion [12]. Partial or complete loss of control may be the secondary result of either small aircraft structural impact or large aircraft jet engine ingestion [11]. Loss of flight instrument function 
can be caused by impact effects on the Pitot Static System (A system pressure-sensitive instruments which is used to determine an aircraft's airspeed, Mach number and altitude) [11]. Complete Engine failure or serious power loss, even on only one engine, may be critical during the take-off phase for aircraft [11].

An example related to the type of damages that occurs during a Bird Strike is depicted in the figure below.

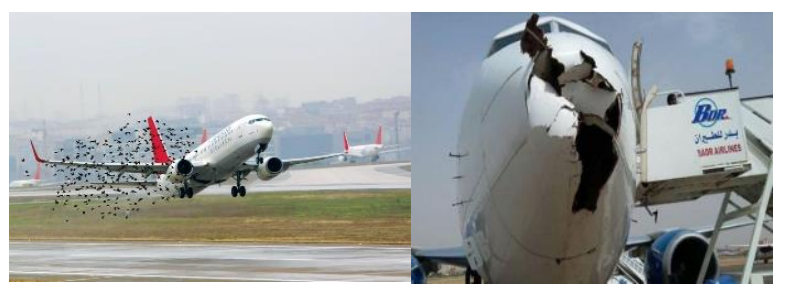

Fig 1. An example of Bird Strike and damage to the plane

According to a research the point of impact is usually any forward-facing edge of the vehicle such as a wing leading edge, nose cone, jet engine cowling or engine inlet [18]. Taking an example of the impact caused due to the Jet Engine ingestion is explained in the below context.

Jet engine ingestion is extremely serious due to the rotation speed of the engine fan and engine design. As the bird strikes a fan blade, that blade can be displaced into another blade and so forth, causing a cascading failure [18]. Jet engines are particularly vulnerable during the takeoff phase when the engine is turning at a very high speed and the plane is at a low altitude where birds are more commonly found [18].

The figure below depicts the effects caused by Bird Strike on the Jet Engine part of the aircraft. A bird of size not comparable to the aircraft can cause enormous damage is an astonishing matter. The science behind this explained in the next context.
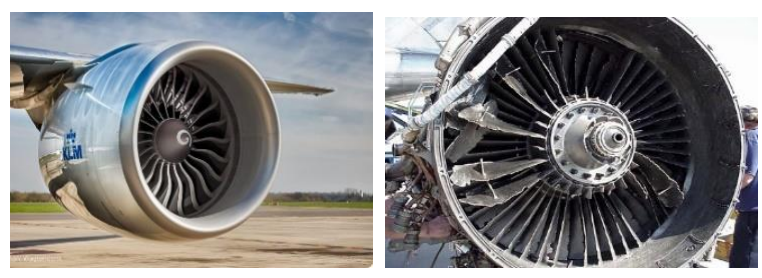

Fig 2. Normal Jet Engine [20] Fig 3. Jet Engine after Bird Strike [21]

The force of the impact on an aircraft depends on the weight of the animal and the speed difference and direction at the point of impact [18]. The energy of the impact increases with the square of the speed difference [18]. High-speed impacts, as with jet aircraft, can cause considerable damage and even catastrophic failure to the vehicle [18]. The energy of a $5 \mathrm{~kg}$ (11 pounds) bird moving at a relative velocity of 275 kilometer/hour (171 miles per hour) approximately equals the energy of a 100 kilograms (220 pounds) weight dropped from a height of 15 meters (49 feet) [18].

At normal speeds, during a perfectly inelastic collision an object struck by a projectile will deform, and this deformation will absorb most or all of the energy due to the force of the collision and when it is viewed from a conservation of energy perspective, the kinetic energy of the projectile is changed into heat and sound energy, as a result of the deformations and vibrations induced in the struck object [3]. However, these deformations and vibrations cannot occur instantaneously because a highvelocity collision does not provide sufficient time for these deformations and vibrations to occur [3]. Thus, the struck material behaves as if it were more brittle than it would otherwise be, and the majority of the applied force goes into fracturing the material [3].

Taking into heed to the above matter, different approaches were taken into consideration for improving the harmful effects caused to both birds and the aircraft.

\section{Approaches towards Prevention of Bird Strike}

Knowing the various impacts caused due to Bird Strike, aerodromes have applied some techniques to detect the birds and their activities which can help the aerodrome authorities to take certain measures before the Take-Off or Landing of any aircraft.

Detection of Birds applied by Aircraft Institutes during Flight [10]:

i. Visual: Birds seen in close proximity to the airplane or colliding with the airplane will be noticed along with bird remains on windshield, cracked windshield. A next step will be taken to avoid these occurrences [10].

ii. Tactile: When there is vibration of airframe or engine, thrust loss, asymmetric thrust, increased drag, abnormal airplane handling characteristics, the pilot will sense these by using tactile sensing devices. This alerts the pilot that the flight is in an uncoordinated condition and must be corrected [10].

iii. Auditory: Noise of strike or noise attributed to resulting damage such as engine surging, compressor stalls, aerodynamic noise from damaged radome (aerodynamically shaped dome which protects the radar situated within the aircraft), loss of pressurization from pressure 
vessel penetration indicates the pilot, some dangerous states of the flight [10].

iv. Olfactory: Smoke, odor, or cooked bird smell gives a sense of alert [10].

v. Engine indications: Reduction or fluctuation in primary power parameter (e.g., engine pressure ratio, fan speed, or equivalent), abnormal fuel flow, abnormal engine vibration monitoring (e.g., error vector magnitude or equivalent), engine failure, engine exceedances [10].

vi. Flight instruments: Loss of data or erroneous indications arising from damage to air data sensors or angle-of-attack sensors [10].

vii. Other airplane systems or structure affected directly by a strike: Damaged communications or navigation antennas, damage to exposed electrical wiring or hydraulic lines, damaged radome or weather radar, broken landing lights, or cascading and multiple effects from sensor damage or engine damage [10].

Along with several detection measures there is another method to prevent the Bird Strike during the Take-Off, i.e. to decide whether to continue the flight or report an emergency landing after a Bird Strike has occurred.

Bird Strike during Take-Off: If a bird strike occurs during Take-Off, the decision to continue or reject the Take-Off is made using the criteria found in the Rejected Take-Off maneuver of the QRH (Quick Reference Handbook contains all the procedures applicable for abnormal and emergency conditions in an easy-to-use format) [10]. If a bird strike occurs above 80 knots and prior to $\mathrm{V} 1$, and there is no immediate evidence of engine failure (e.g., failure, fire, power loss, or surge/stall), the preferred option is to continue with the takeoff followed by an immediate return, if required [10]. On $8^{\text {th }}$ August,2020 an AirAsia flight Take-Off was aborted due to a Bird Strike hence saving aircraft damage and the passengers within the aircraft.

After discussing the various methods to detect the birds and their activities, several preventive measures have also been applied in the past few years. These measures have been listed below.

i. Field observations from control tower of aerodrome, inspection of infield areas and survey of buffer zone areas, $25 \mathrm{~km}$ in radius of the aerodrome to locate areas of bird activity and to find out the reasons for attracting birds and how these birds become a hazard to aircraft [1].

ii. Gathering bird strike data and bird strike remnants on a national level and from each aerodrome whenever survey was conducted [1]. iii. Propane scare cannons are one of the most common types of bird scaring device. The audible bang can reach very loud volumes, in excess of 150 decibels, causing a flight reaction in birds. Propane scare cannons are very loud and can be disruptive to people living nearby [13].

iv. Cartridge scaring device include a wide variety of noise-producing cartridges usually fired from rockets or rope bangers, or on aerodromes from modified pistols or shotguns, which produce a loud bang and emit flashes of light [13].

v. The use of lasers can be an effective method of bird scaring, although there is some evidence to suggest some birds are "laser-resistant". As the effectiveness of the laser decreases with increasing light levels, it is likely to be most effective at dawn and dusk [13].

vi. Present method used by pilots to send away birds is switching on the lights while take-off and landing phases of flying.

An avian radar system tracks birds or other airborne targets within its 3-D surveillance volume, characterized by a cylinder with an approximate range up to 10 kilometers and up to 10,000-foot altitude above ground level. Special scanning methods form 3-D target trajectories using track data and volume-revisit times. Regular updates provide situational awareness of developing hazards, allowing operators to take action [19].

Harassment and dispersal are critical for immediate hazard management hence an Airport personnel charged with this responsibility should apply various devices and techniques in varied ways because reliance on only one or two devices quickly results in habituation by birds, significantly reducing their effectiveness, and ultimately having minimal, or no, influence on the strike rate [2]. Dispersal tools may include, but not be limited to, distress callers, lights, pyrotechnics, gas canons, lasers, falconry, remote controlled devices, dogs, stock whips, whistle, vehicles and sirens [2].

Due to rapid habituation to static devices, these are not recommended for use [2]. This is proved in the below context.

Even after applying these methods to detect and prevent Bird Strikes, the count of Bird Strike did not reduce as we see in the below research, which shows a recent count of Bird Strikes in few metro cities.

In 2019, 1,280 wildlife-strikes occurred at all airports, slightly lower than 1,320 in 2018. In 2017, the number of incidents stood at 1,125, while in 2016 it was 839 in India [17].

The Ministry of Civil Aviation and the Directorate General of Civil Aviation have recognized wildlife strikes, including bird and animal hits, to aircraft as one of the "State Safety Priority", and the aviation regulator 
regularly carries out aerodrome inspection that considered critical in with regard to wildlife strikes [17].

The table below shows a decrease in the number of Wildlife Strike but still it is not an effective decrease. Hence this shows that the current measures taken are inefficient and requires a better technique to reduce these strikes.

Table 1: Recent Wildlife Strike statistics [14]

\begin{tabular}{|c|c|c|c|c|}
\hline Airports & $\mathbf{2 0 1 9}$ & $\mathbf{2 0 1 8}$ & $\mathbf{2 0 1 7}$ & $\mathbf{2 0 1 6}$ \\
\hline Ahmedabad & 10.96 & 14.89 & 11.61 & 13.26 \\
\hline Goa & 7.36 & 7.44 & 5.94 & 3.29 \\
\hline Delhi & 5.36 & 4.75 & 5.17 & 3.54 \\
\hline Mumbai & 2.38 & 3.16 & 2.45 & 2.44 \\
\hline Bangalore & 1.58 & 3.05 & 1.80 & 2.67 \\
\hline Hyderabad & 2.21 & 4.21 & 4.26 & 3.38 \\
\hline Chennai & 3.16 & 4.48 & 3.06 & 2.98 \\
\hline Kolkata & 2.88 & 5.23 & 3.80 & 3.47 \\
\hline
\end{tabular}

Note: Data as per 10,000 flights

A novel approach taking into all other approaches into matter is to use 'special sound' which disturbs the birds but does not harm them. This special sound is Ultrasound which varies in frequency from 15 Kilo hertz to 30 Kilo hertz. Ultrasound is a sound wave with frequencies higher than upper audible limit of human hearing (i.e. 20 Hertz to 20 Kilo hertz). Though it has physical characteristics similar to the audible hearing of humans, it is inaudible to humans.

Ultrasound belongs to the long wave region of the spectrum (i.e. short frequency). The advantage of long waves being, less attenuation in free space compared to short waves or high frequency signals. This one characteristic of ultrasound ensures effective transmission in free space with comparatively less attenuation.

Ultrasound has till now being used to detect cracks in metals or other faults and another important application is in the medical field called as sonography. A new field for application of ultrasound has been initiated in scaring the birds and preventing Bird Strike.

The speed of ultrasound in air is 1108 Kilo meter/hour which is much greater than the speed of aircraft during
Take-Off or Landing which is approximately 240-285 kilometer/hour. Hence these signals radiate faster than the Take-Off of the aircraft.

The ultrasonic radiations produced will be radiated through piezo speakers. These radiating devices must be placed in the respected aircrafts which will be turned ON during Take-Off and Landing.

Range of ultrasonic device - 50 feet (15 meter). For real time applications we need to design a device which covers a distance of $10 \mathrm{~km}$.

\section{LITERATURE SURVEY}

The new approach initiated has been put into progress after a survey of varied techniques which provides a green signal in using ultrasonic radiations for scaring away birds. Bird Strike, which doesn't sound as a crucial global cause has become a nerve striking problem for all the Aeronautical institutes. The importance of conducting survey of problem within the aerodromes every five years by an expert is now a necessity which has employing an Ornithologist at every aerodrome, need for normal national-level training for bird-controllers and urgency for fixing Bird-strike Prevention Committees at national and airport levels depicted by S. M. Satheesan et al (1999) [1]. A data represented few techniques which was surveyed by S. M. Satheesan et al (1999) [1] and it consisted of the following: i. Field observations from tower of aerodrome and inspection within $25 \mathrm{~km}$ in radius of the aerodrome to locate areas of bird activity and to seek out out the explanations for attracting birds and the way these birds become a hazard to aircraft and hence decision of aircraft timings will be altered or withheld. ii. Gathering bird strike data and bird strike remnants on a national level and from each aerodrome whenever survey was conducted. This step helps in knowing the aerodromes which have greater concentration of bird habitats and therefore the rate of the aerodrome to be easily suffering from Bird Strike. iii. Evaluating efficacy of bird repelling cartridges, other devices and machines additionally as herbicides and insecticides. iv. Providing practical, cheap, long-lasting, ecologically and environmentally sound measures like modifications to cut back water-logging, instituting effective system, mowing vegetation cover, erecting tall barbed fences, repairing breached concrete boundary walls and shutting down of a bird-attracting waste-yard very near a runway end, to tackle bird menace to aircraft in and around aerodromes and evaluating these recommendations from time to time.

Conducting a survey of Bird Strike is a crucial task because it is causing enormous damage to some parts of the aircraft hence becoming a threat for a secure flight. an exploration shows few of the parts which are highly liable to Bird Strike damage depicted in Fig 4. Zdobyslaw Goraj, Kamila Kustron et al (2018) [3] focuses on summarizing 


\section{International Journal of Engineering Applied Sciences and Technology, 2020 \\ Vol. 5, Issue 3, ISSN No. 2455-2143, Pages 208-224 \\ Published Online July 2020 in IJEAST (http://www.ijeast.com)}

current research trends in bird strike and hail impact simulations on vanguard (LE) and on expectations of all stakeholders in civil aviation that safety must be increased. According to Zdobyslaw Goraj, Kamila Kustron et al (2018) [3] there are four ways to scale back the effect of the bird-strike: i. the aircraft will be designed to be bird-strike resistant, ii. the aircraft can have lower speed during critical phases of flight iii. the birds are often quarantined of the way of the aircraft iv. the aircraft may be abstracted of the way of the birds. There are two different strategies from the regulatory side used for birdstrike risk mitigation in aviation [3]. the primary strategy relates to the look of the forward-facing aircraft components to fulfill resistance to impact so as for them to become them resilient and fewer prone to the incidents concentrating on a way to strengthen aerostructure designs to attenuate damage and ensure safety. It includes the activities associated with passive safety. Aviation authorities require that wing LEs must prove a specific level of bird strike resistance in certification tests before the aircraft is permitted to travel into service. during this particular strategy the stronger the components are made the more resistant they become. to extend the resistance a heavier component material are going to be necessary, which causes a controversy in an exceedingly normal Take-Off because the aircraft becomes heavier. The second strategy is targeted on reducing aircraft exposure to bird strikes. because the problem is especially associated with take-offs and landings, the strategy concentrates on the actual conditions of airports and also the have to applicate the active safety solutions. this is often the strategy we are visiting apply to scale back the Bird Strike. Another simple technique to frighten away the birds was to reinforce aircraft visually through a bright colour scheme might facilitate a bird's ability to detect and distinguish aircraft shape in time to perform avoidance behavior researched and applied by Isabel C. Metz, Joost Ellerbroek, Thorsten Mühlhausen, Dirk Kügler, Jacco M. Hoekstra et al (2020) [4]. For turboprop aircraft, such a bearing is gained by applying colored patterns to the propeller to boost the aircraft's contrast against the sky. Research on increasing aircraft lighting found that pulsing light has the potential to reinforce avian visual awareness. However, as seeing depends on the bird species, different pulsing frequencies and wavelengths may be required. An experiment identified that certain wavelengths do trigger strong avoidance reactions of birds, while other wavelengths didn't cause any behavioral response. this means that the selection of lights to be installed can support successful collision avoidance. Radio Detection and Ranging (RADAR), an invention which gave solutions to varied problems (Detection of aircraft, ships, spacecraft, weather outlook etc.) was also applied within the task of reducing Bird Strike. 'Bird Strike Avoidance Radar' equipment, Jaiye Jehoshaphat
Dukiya, Vimal Gahlot et al (2012) [5], that may alert the tower which can successively alert the pilot of the presence of birds along his way be installed in major airports within the country. Since modern aircraft aren't any longer noisy to dash most birds, bird repellents should be built into aircraft and airports. The Bird/Wildlife Hazard Control (B/WHC) unit of all the nations' international airports should be trained and equipped with current equipment which will repel birds round the ports. RADAR is one among the methods which is currently dominating all other techniques of reducing Bird Strike because it has proven to be effective to a good extent. But the sole drawback is that the message sent via RADAR are often delayed hence the pilot may receive the message at the incorrect time and thus resulting in a mismatched situation. Similar to Aviation institutes, even crop fields and Transmission lines also face problems by birds. Hence Fuliang Le, Jiawei Luo, Gongping Wu et al (2009) [6] came up with three different techniques to displace the birds including an induction compensating power to resolve the matter of acquiring power. The induction compensating power can transform magnetic energy around transmission lines to electricity for batterycharge, therefore the bird repeller can work uninterruptedly on the transmission lines. the facility consumption is not up to the traditional repeller and hence the equipment can work uninterrupted with lighter battery by using ICP as compensating power. Keeping aside the facility saving a part of their experiment and concentrating on three methods of driving away the birds which includes; Sound shock, Ultrasonic shock and Electric shock. The Sound shock includes producing sounds of howls, tigers or cruel animals when the bird is nearby. the downside of this method is that the birds can get vulnerable to the sounds after long-term usage of this method. The Ultrasonic shock includes radiating ultrasonic waves because of which the birds get a disturbed feeling which was explained by Dr. Whitford [22]. the electrical shock includes producing high voltage signals when the birds are nearby. This cause an enormous impact on the lives of birds because it are often highly dangerous to their livelihood.

A similar area of bird problem is that the crop fields which are highly suffering from their activities. Another prototype involving Ultrasonic radiations, Yahot Siahaan, Bheta Agus Wardijono and Yulisdin Mukhlis et al (2017) [7] has used a motion detection system which then proceeds to a repellent that generates a selected frequency, that the bird are visiting be disturbed. This prototype consists of PIR sensors as a detector to detect movement from birds and using LC oscillator type Colpitts with Piezo Ultrasonic sensor as repeller. The results of the experiment are the PIR sensor working with a detection 
distance between $0 \mathrm{~cm}-500 \mathrm{~cm}$, and so the bird are visiting be disturbed at a frequency signal of about 60 $\mathrm{kHz}$. The prototype shows a list of assorted birds getting disturbed at varying frequencies.

Having prototypes which include the usage of ultrasonic radiations for driving away birds, they were ineffective when the deterrent must radiate in multiple directions. Navinesshani Permal, Thiviya Barathi Raja Segaran, Renuga Verayiah, Farrukh Hafiz Nagi, Agileswari K. Ramasamy et al (2019) [8] believed that current available ultrasonic bird deterrent system isn't effective in eliminating bird activity because the signals travel in omnidirectional. Hence an improvised technique was utilized in their prototype which describes the hardware implementation of an ultrasonic bird deterrent system using beamforming method on transmission lines. This method is capable of focusing its wave on the birds and bird nests in an exceedingly particular direction at the transmission lines where it creates discomfort to the birds and hence forcing the birds to evacuate the lines. Ultrasonic sensors are widely utilized in controlling birds at airports and farms. For this, four piezo speakers were place in $90^{\circ}$ to each other to provide a $360^{\circ}$ area coverage for a crop field. This improvisation would help our method to have radiations in multiple directions which provides an honest transmission of radiations.

Similar to the above reference, for effective transmission of radiations in multiple directions another technique for this purpose is expressed in V. Arun pandiyan, J. Murugan Senthamilan, D. Uday Kumar, V. Vinithkumar et al (2019) [9]. During the flight take-off and landing time the birds interrupt the flight engine and causes severe damages to the aircrafts and its finally ends up in accident. Using any pesticides to kill the particular bird and while spraying chemical substance is also a brief solution and these forms of activities don't seem to be good for humans and birds. Bird repellers which are available so far don't seem to be movable so we depend upon more quantities of ultrasonic repellers required to manage large areas. Hence the paper includes the usage of a rover to form the repeller movable.

Each reference within the above context provide numerous data which helps us in building a tool for driving away birds with the help of ultrasonic radiations. the globe problem of the Bird Strike must be reduced to a decent amount for balancing the ecology furthermore as maintaining the quality of the aircrafts. The above survey gives us information about the numerous problems, the measures taken till date, the improvisations provided to the older prototypes with which we collectively come up with a replacement device with new features.

\section{HARDWARE AND SOFTWARE DESCRIPTION}

The project implementation is possible with the appropriate hardware and software tools. The hardware and software tools which are used for this prototype are listed in below context.

\section{Hardware Description}

\section{i. PIC 18F46k22(Microcontroller)}

PIC18F46K22 Micro-controller may be a core of this project. Microcontroller has high computational performance also with the addition of high-endurance. This controller is of 8-bit micro-controller and has 28 pins. PIC microcontrollers (Programmable Interface Controllers), are electronic circuits that may be programmed to hold out an enormous range of tasks. This Microcontrollers are ideal for tiny embedded systems requiring an outsized number of $\mathrm{A} / \mathrm{D}$ inputs, which is on the market at economic range.PIC18F26K22 is an 8-bit microcontroller with 28 pins and it provides noticeable computational performance with non-volatile storage at reasonable price. The Micro-controller has 5 ports which may be used as Input/output pins, which all relies upon on the programmer. The 5 PORTS are named as A, B, C, D and E. Except PORT E remaining 4 PORTS have 8 pins whereas PORT E is supplied with 3 pins. Five ports are allocated with 33 pins and remaining pins are allotted for Master clear Reset Pin (MCLR) which is reset pin i.e. active low input pin (normally high), two sets of VDD (VCC) which operates at maximum $+5 \mathrm{~V}$ and VCC. PIC18 additionally consists OSC1, OSC2 as input pins which is associated frequently to the Crystal crystal oscillator.

PIC18 has 1024 bytes of EEPROM, 64kb of ROM and 4kb RAM. It also has Analog/Digital converter with 30 channels each of 10-bit where a greater number of Analog/Digital inputs are required. It are often programmed in C and ALP language. The speed of PIC18 controller is 16 Million instruction per second during its operation and is additionally given two RS232 connections, SPI and I2C channels.
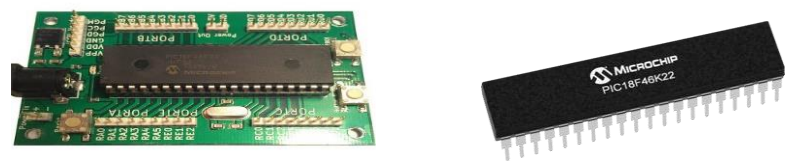

Fig 10. PIC 18F46k22 


\begin{tabular}{|c|c|c|c|c|}
\hline$\overline{\mathrm{MCLR}} / \mathrm{NPP} / \mathrm{RE} 3$ & $\cdot 1$ & & 28 & RB7/PG \\
\hline RAO & 2 & & 27 & RB6/PG \\
\hline RA1 & 3 & & 26 & RB5 \\
\hline RA2 [ & 4 & & 25 & RB4 \\
\hline RA3 & 5 & บั & 24 & RB3 \\
\hline RA4 & 6 & $\frac{x}{x}$ & 23 & RB2 \\
\hline RA5 & 7 & กิ & 22 & RB1 \\
\hline Vss & 8 & ב & 21 & RBO \\
\hline RA7 & 9 & $\infty$ & 20 & VDD \\
\hline RA6 & 10 & $\overline{0}$ & 19 & Vss \\
\hline $\mathrm{RCO}$ & 11 & $\frac{0}{\alpha}$ & 18 & $\mathrm{RC} 7$ \\
\hline RC1 & 12 & & 17 & RC6 \\
\hline $\mathrm{RC} 2$ & 13 & & 16 & RC5 \\
\hline $\mathrm{RC} 3$ & 14 & & 15 & $\mathrm{RC} 4$ \\
\hline
\end{tabular}

Fig 11. Pin Configuration of PIC 18F46k22

Table 2. Description of three PORTS of the 28-pin PIC 18F46k22

\begin{tabular}{|c|l|}
\hline PORTS & \multicolumn{1}{c|}{ Description } \\
\hline PORT A & $\begin{array}{l}\text { PORTA is an 8-bit wide, bidirectional port. } \\
\text { The corresponding data direction register is } \\
\text { TRISA. Setting a TRISA bit (= 1) will make } \\
\text { the corresponding PORTA pin an input (i.e., } \\
\text { disable the output driver). } \\
\text { Clearing a TRISA bit (= 0) will make the } \\
\text { corresponding PORTA pin an output (i.e., } \\
\text { enable the output driver and put the contents } \\
\text { of the output latch on the selected pin). }\end{array}$ \\
\hline PORT B & $\begin{array}{l}\text { PORTB is an 8-bit wide, bidirectional port. } \\
\text { The corresponding data direction register is } \\
\text { TRISB. Setting a TRISB bit (=1) will make } \\
\text { the corresponding PORTB pin an input (i.e., } \\
\text { disable the output driver). } \\
\text { Clearing a TRISB bit (=0) will make the } \\
\text { corresponding PORTB pin an output (i.e., } \\
\text { enable the output driver and put the contents } \\
\text { of the output latch on the selected pin). }\end{array}$ \\
\hline PORT C & $\begin{array}{l}\text { PORTC is an 8-bit wide, bidirectional port. } \\
\text { The corresponding data direction register is } \\
\text { TRISC. Setting a TRISC bit (=1) will make } \\
\text { the corresponding PORTC pin an input (i.e., } \\
\text { disable the output driver). } \\
\text { Clearing a TRISC bit (=0) will make the } \\
\text { corresponding PORTC pin an output (i.e., } \\
\text { enable the output driver and put the contents } \\
\text { of the output latch on the selected pin). } \\
\text { PORTC is multiplexed with several } \\
\text { peripheral functions. The pins have Schmitt } \\
\text { Trigger input buffers. }\end{array}$ \\
\hline
\end{tabular}

Note: TRIS (Tri-state) register controls the data direction, i.e. controls whether the digital I/O pin is an input or output.
PIC18F26K22 controller is main component in this project which operates at the speed of 0 to $40 \mathrm{GHz}$. All the port is provided with 4 SFRs (Special Function Registers) namely TRISx, LATx, PORTx, ANSELx, where ' $\mathrm{x}$ ' stands for type of PORT.

Table 3. Pin Configuration of PIC 18F46k22

\begin{tabular}{|c|c|c|}
\hline $\begin{array}{c}\text { Pin } \\
\text { Number }\end{array}$ & Pin Name & Description \\
\hline 1 & $\begin{array}{c}\text { MCLR } \\
\text { bar/VPP/RE3 }\end{array}$ & $\begin{array}{l}\text { MCLR bar: It is an optional } \\
\text { external reset that is activated by } \\
\text { pulling the pin low. } \\
\text { VPP: programming voltage } \\
\text { input. } \\
\text { RE3: I/O of port E. }\end{array}$ \\
\hline $2-7,9,10$ & RA0 to RA5 & $\begin{array}{l}\text { I/O pin of PORTA; used as } \\
\text { comparator inputs or outputs by } \\
\text { setting the appropriate bits } \\
\text { The RA4 pin is multiplexed } \\
\text { with the Timer0 module clock } \\
\text { input and one of the comparator } \\
\text { outputs } \\
\text { Pins RA6 and RA7 are } \\
\text { multiplexed with the main } \\
\text { oscillator pins. }\end{array}$ \\
\hline 8 & VSS & $\begin{array}{l}\text { It is referred as the common or } \\
\text { the ground pin ( } 0 \text { volts). }\end{array}$ \\
\hline $11-18$ & $\mathrm{RC} 0$ to $\mathrm{RC} 7$ & $\mathrm{I} / \mathrm{O}$ pin of PORTC \\
\hline 19 & VSS & $\begin{array}{l}\text { It is referred as the common or } \\
\text { the ground pin ( } 0 \text { volts). }\end{array}$ \\
\hline 20 & VDD & Positive Power Supply (+5V) \\
\hline $21-26$ & RB0 to RB5 & $\mathrm{I} / \mathrm{O}$ pin of $\mathrm{PORTB}$ \\
\hline 27 & RB6/ PGC & $\begin{array}{l}\text { I/O pin of PORTB; } \\
\text { PGC- In-Circuit Debugger and } \\
\text { ICSP programming clock pin. }\end{array}$ \\
\hline 28 & RB7/ PGD & $\begin{array}{l}\text { I/O pin of PORTB; } \\
\text { PGD- In-Circuit Debugger and } \\
\text { ICSP programming data pin. }\end{array}$ \\
\hline
\end{tabular}

Note: MCLR bar- Master Clear Reset; PORT- reads the levels on the pins of the device; PGC-Clock; PGD- Data;

ICSP (In-Circuit Serial Programming)- A debugger, emulator and programmer use a serial signaling scheme to program a target device incircuit. The signals PGC and PGD are active bidirectional signals driven by the tool and target device during a typical programming or debugging session.

Source: Microchip data sheet [25]; Microchip Developer help [26] 


\section{ii. HC-SR04(Piezo ultrasonic speaker)}

HC-SR04 could be a piezo speaker. A piezo electric material could be a non-conductive material which produces electricity when the fabric undergoes mechanical stress. The materials may also deform when field of force is applied thereto. The word 'piezo' refers to applying pressure or squeezing within. The HC-SR04 Ultrasonic distance sensor consists of two ultrasonic transducers. The one acts as a transmitter which converts electrical signal into $40 \mathrm{KHz}$ ultrasonic sound pulses as shown within the Fig 4.1.2. The receiver listens for the transmitted pulses. If it receives them it produces an output pulse whose width will be accustomed determine the gap the heartbeat travelled [27].
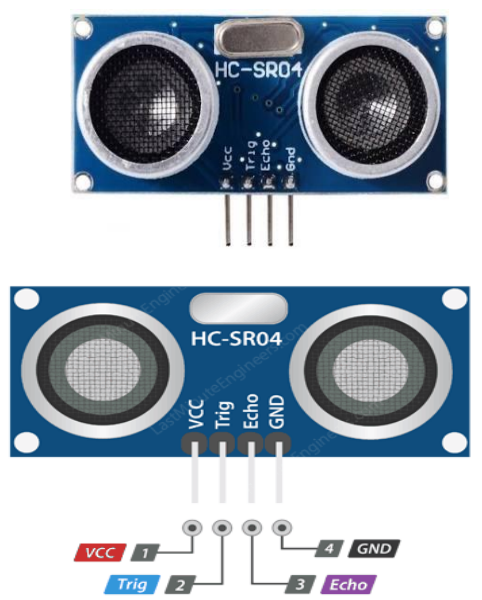

Fig 11. Piezo Electric Speaker

Table 4. Pin Configuration of HC-SR04 [28]

\begin{tabular}{|c|c|l|}
\hline Pin & Pin & \multicolumn{1}{c|}{ Description } \\
\hline 1 & VCC & $\begin{array}{l}\text { The Vec pin powers the sensor, } \\
\text { typically with +5V. }\end{array}$ \\
\hline 2 & Trigger & $\begin{array}{l}\text { Trigger pin is an Input pin. } \\
\text { This pin has to be kept high for } \\
\text { 10us to initialize measurement } \\
\text { by sending US wave. }\end{array}$ \\
\hline 3 & Echo & $\begin{array}{l}\text { Echo pin is an Output pin. } \\
\text { This pin goes high for a period } \\
\text { of time which will be equal to } \\
\text { the time taken for the US wave } \\
\text { to return back to the sensor. }\end{array}$ \\
\hline 4 & Ground & $\begin{array}{l}\text { This pin is connected to the } \\
\text { Ground of the system. }\end{array}$ \\
\hline
\end{tabular}

The ultrasonic transducer is used to radiate the generated frequency. The VCC pin is connected to VCC ( +5 Volts) and GND is connected to ground. The RC2 pin of the microcontroller is usually used as an output pin hence it is connected to the Trigger pin of the Piezo speaker as it is an input pin. The echo pin is connected to the RB4 pin of the microcontroller.

\section{iii. HC-05(Bluetooth)}

The HC-05 may be a very useful module which may add two-way (full-duplex) wireless functionality to any project. you'll use this module to speak between two microcontrollers or communicate with any device with Bluetooth functionality sort of a Phone or Laptop. There are many android applications that are already available which makes this process lots easier. The module communicates with the assistance of USART at 9600 baud-rate hence it's easy to interface with any microcontroller that supports USART. we are able to also configure the default values of the module by using the command mode. It works well as a Wireless module that might transfer data from your computer or itinerant to microcontroller or the other way around [29].

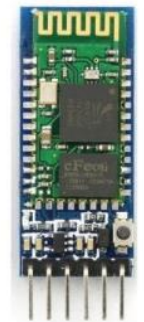

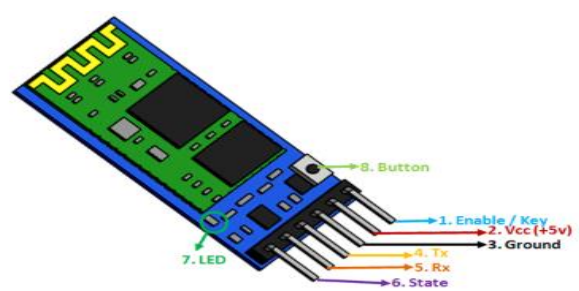

Fig 12. HC-05 Bluetooth 
Table 5. Pin configuration of HC-05 [29]

\begin{tabular}{|c|c|c|}
\hline $\begin{array}{c}\text { Pin } \\
\text { Number }\end{array}$ & $\begin{array}{c}\text { Pin } \\
\text { Name }\end{array}$ & Description \\
\hline 1 & Enable/Key & $\begin{array}{l}\text { This pin is used to toggle } \\
\text { between Data Mode (set low) } \\
\text { and AT command mode (set } \\
\text { high). By default, it is in Data } \\
\text { mode }\end{array}$ \\
\hline 2 & $\overline{\mathrm{VCC}}$ & $\begin{array}{l}\text { Powers the module. Connect to } \\
+5 \mathrm{~V} \text { Supply voltage }\end{array}$ \\
\hline 3 & Ground & $\begin{array}{l}\text { Ground pin of module, connect } \\
\text { to system ground. }\end{array}$ \\
\hline $\begin{array}{c}\text { Pin } \\
\text { Number }\end{array}$ & $\begin{array}{c}\text { Pin } \\
\text { Name }\end{array}$ & Description \\
\hline 4 & Transmitter & $\begin{array}{llr}\text { Transmits } & \text { Serial } & \text { Data. } \\
\text { Everything } & \text { received } & \text { via } \\
\text { Bluetooth will be given out by } \\
\text { this pin as serial data. }\end{array}$ \\
\hline 5 & Receiver & $\begin{array}{l}\text { Receive Serial Data. Every } \\
\text { serial data given to this pin will } \\
\text { be broadcasted via Bluetooth }\end{array}$ \\
\hline 6 & State & $\begin{array}{l}\text { The state pin is connected to on } \\
\text { board LED, it can be used as a } \\
\text { feedback to check if Bluetooth } \\
\text { is working properly. }\end{array}$ \\
\hline 7 & LED & $\begin{array}{l}\text { Indicates the status of Module } \\
\text { Blink once in } 2 \text { sec: Module has } \\
\text { entered Command Mode } \\
\text { Repeated Blinking: Waiting for } \\
\text { connection in Data Mode } \\
\text { Blink twice in } 1 \text { sec: Connection } \\
\text { successful in Data Mode }\end{array}$ \\
\hline 8 & Button & $\begin{array}{l}\text { Used to control the Key/Enable } \\
\text { pin to toggle between Data and } \\
\text { command Mode }\end{array}$ \\
\hline
\end{tabular}

The HC-05 has two operating modes, data mode (default mode) or the AT command mode. The Bluetooth employed in this project is to attach the appliance to the microcontroller PIC18. during this the Enable/Key is kept within the default mode, i.e. the information mode. This
Bluetooth module sends the info (frequency set within the mobile application) to the microcontroller for further processing.

\section{iv. LCD display}

A liquid-crystal display (LCD) is a flatpanel display devices that uses the light modulating properties of liquid crystals. Liquid crystals don't emit light directly, instead employing a backlight or reflector to provide images in color or monochrome.

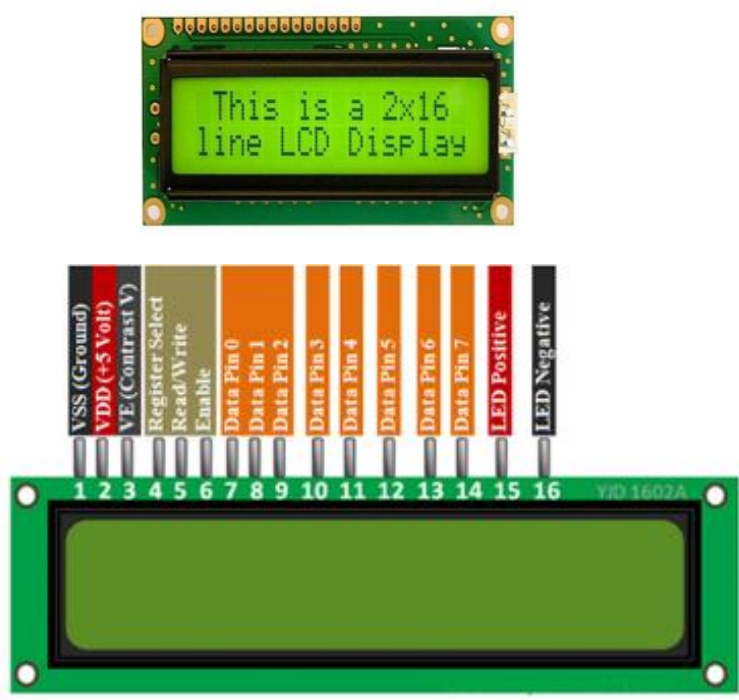

Fig 13. 16x2 LCD Display

Table 6. Pin Configuration of LCD [30]

\begin{tabular}{|c|c|l|}
\hline Pin & Pin Name & \multicolumn{1}{|c|}{ Description } \\
\hline 1 & VSS & $\begin{array}{l}\text { Ground pin connected to } \\
\text { system ground }\end{array}$ \\
\hline 2 & VDD & $\begin{array}{l}\text { Powers the LCD with +5V } \\
(4.7 \mathrm{~V}-5.3 \mathrm{~V})\end{array}$ \\
\hline 3 & VE (Contrast & $\begin{array}{l}\text { Decides the contrast level } \\
\text { of display. Grounded to get } \\
\text { maximum contrast. }\end{array}$ \\
\hline 4 & Register & $\begin{array}{l}\text { Connected to } \\
\text { Sicrocontroller to shift } \\
\text { between command/data } \\
\text { register }\end{array}$ \\
\hline 5 & Read/Write & $\begin{array}{l}\text { Used to read or write data. } \\
\text { Normally grounded to write } \\
\text { data to LCD }\end{array}$ \\
\hline
\end{tabular}




\begin{tabular}{|c|c|l|}
\hline 6 & Enable & $\begin{array}{l}\text { Connected to } \\
\text { Microcontroller Pin and } \\
\text { toggled between 1 and 0 for } \\
\text { data acknowledgement }\end{array}$ \\
\hline 7 to 14 & Data Pin 0-7 & $\begin{array}{l}\text { Data pins 0 to 7 forms an 8- } \\
\text { bit data line. They can be } \\
\text { connected to } \\
\text { Microcontroller to send 8- } \\
\text { bit data. } \\
\text { These LCD's can also } \\
\text { operate on 4-bit mode in } \\
\text { such case Data pin 4,5,6 } \\
\text { and 7 will be left free. }\end{array}$ \\
\hline Pin & Pin Name & Description \\
\hline 15 & LED Positive & $\begin{array}{l}\text { Backlight LED pin positive } \\
\text { terminal }\end{array}$ \\
\hline 16 & LED & $\begin{array}{l}\text { Backlight LED pin negative } \\
\text { terminal }\end{array}$ \\
\hline
\end{tabular}

The LCD used in this context is to display the frequency generated by the microcontroller through PWM generation.

\section{v. Driver circuit}

In electronics, a driver is a circuit or component used to control another circuit or component, such as a highpower transistor, liquid crystal display (LCD), and numerous others. Typically, the driver stage(s) of a circuit requires different characteristics to other circuit stages.

\section{vi. Push Buttons}

A push-button or just button could be a simple switch mechanism to regulate some aspect of a machine or a process. Buttons are usually made out of plastic or metal. The surface is shaped to accommodate the human finger or hand, so it can be easily pushed. Buttons are most frequently biased switches, although many un-biased buttons still require a spring to return to their un-pushed state. These are basic data input device in an embedded system seen in very simple to highly complex systems. they're the fundamental mechanical on-off buttons which act as control devices. It short circuits the road when it's pressed and opens when it's not pressed.

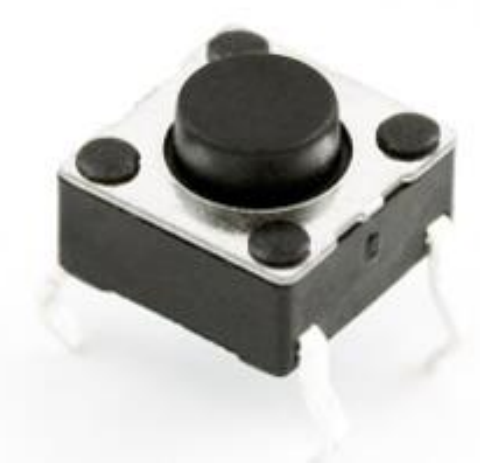

Fig 14. Push button switch

\section{Software Description}

$$
\text { i. } \quad \text { Embedded C }
$$

Embedded C Programming is that the soul of the processor functioning inside each and each embedded system we bump into in our way of life, like mobile washer, and camera. Each processor is said to an embedded software. The first thing is that the embedded software that decides functioning of the embedded system. Embedded C language is most frequently accustomed program the microcontroller. The embedded system designers must realize the hardware architecture to place in writing programs. Programs are important for monitoring and controlling external devices. They also directly operate and use the inner architecture of the microcontroller, like interrupt handling, timers, serial communication and other available features. It support enhanced microprocessor features like fixed-point arithmetic, etc. and basic Input Output operations. Programming PIC $18 \mathrm{MCU}$ is finished utilizing MP lab IDE v8.70. Microchip's fast glimmer sequential bootloader AN1310.

MP LAB IDE: Microchip Technology has founded a notoriety for its exhaustive arrangement of world-class, minimal effort, simple to-utilize application advancement apparatuses. The MPLAB confirmed devices help framework fashioners rapidly configuration, troubleshoot and program PIC and DSPIC microcontrollers for explicit applications. MPLAB IDE could be a software program that's introduced to run on a pc application for microchip microcontrollers.so the name Integrated Development Environment (IDE), As shown in Fig 4.2, MPLAB Integrated Development Environment (IDE) is Microchip's free, coordinated toolset for the advancement of PIC microcontroller and DSPIC computerized signal controller installed applications. MPLAB IDE runs as a 32-piece application on MS Windows, is anything but difficult to utilize and incorporates an outsized group of 
free programming segments for quick application improvement and super-charged investigating. MPLAB IDE in like manner fills in as a singular, united graphical UI for added Microchip and pariah programming/hardware improvement mechanical assemblies. Moving between instruments is easy, and upgrading from the free test framework to MPLAB InCircuit Debugger (ICD) 2 or the MPLAB In-Circuit Emulator (ICE) is straightforward, since MPLAB IDE incorporates a comparable (UI)to all gadgets.

MPLAB®C18 Compiler for PIC18 Microcontroller: The MPLAB C18 compiler is a full-highlighted ANSI consistent C compiler for elite PIC18 8-piece microcontrollers. The 32-piece Windows comfort application is a completely incorporated segment of Microchip's MPLAB IDE, permitting source level troubleshooting with the MPLAB ICE, the MPLAB ICD 2 and the MPLAB SIM Projects. Compiler switches and linker customizations should be possible totally inside MPLAB IDE to give a full graphical front end to this amazing compiler. Altering mistakes and breakpoints quickly change to relating lines in source code. Watch windows show information structures with characterized information types, including coasting point. MPLAB IDE is OS based Integrated Development Environment for the PICmicro MCU families and the dsPIC Digital Signal Controllers.

\section{ii. APP Development}

MIT App Inventor is an intuitive, visual programming method that is used to make fully functional apps for smartphones. With MIT App Inventor an app can be build and used in less than 30 min .Blocks-based tool facilitates the creation of complex, high-impact apps in less time than traditional programming methods. The MIT App Inventor project seeks to democratize software development by empowering all people, especially children, to maneuver from technology consumption to technology creation.

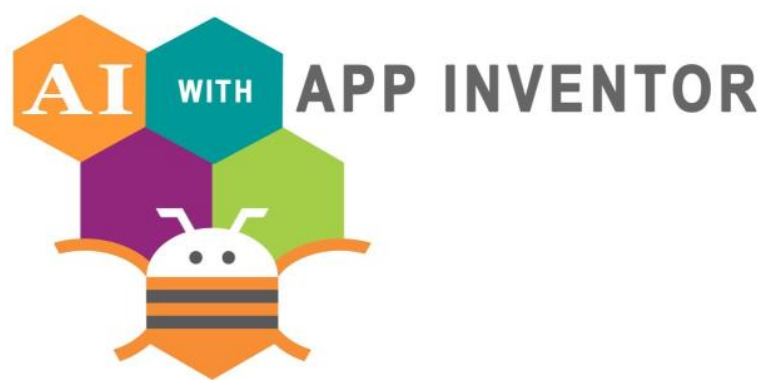

Fig 15. MIT APP Inventor

\section{METHODOLOGY}

After seeking the data and also the properties of Ultrasound and its impact on birds we'd prefer to maneuver forward to develop the device generating these frequencies and diverging them out. Ultrasonic waves are generated by transducer that has a crystal that converts power (electric current) to energy (sound waves) [10]. Ultrasonic repellents area unit a necessity in aeronautical institutes throughout the Take-Off and Landing periods of aircrafts. due to the Bird Strikes caused it creates an imbalance within the eco system destroying the bird life and additionally affects the aircraft infrastructure. Looking forward to the dimensions of the aircraft, one speaker for emitting ultrasonic waves doesn't satisfy the requirements. Hence, phased array within the context of an array of ultrasonic speakers is steered to point in several directions without moving the speakers [5]. A phasedarray transducer encompasses a small footprint, but the ultrasound beam is steered electronically to provide a sufficiently wide far field of view. The ultrasound beam diverges from virtually the identical point within the transducer [12]. Hence making the ultrasonic waves radiate in multiple directions is that the next motive after generating them. As we've got discussed within the above context within the section 'Impacts of Bird Strike' regarding the damages caused to the aircraft, the Fig 4 shows which are parts of the aircraft which are highly liable to Bird Strike and leading to an enormous damage.

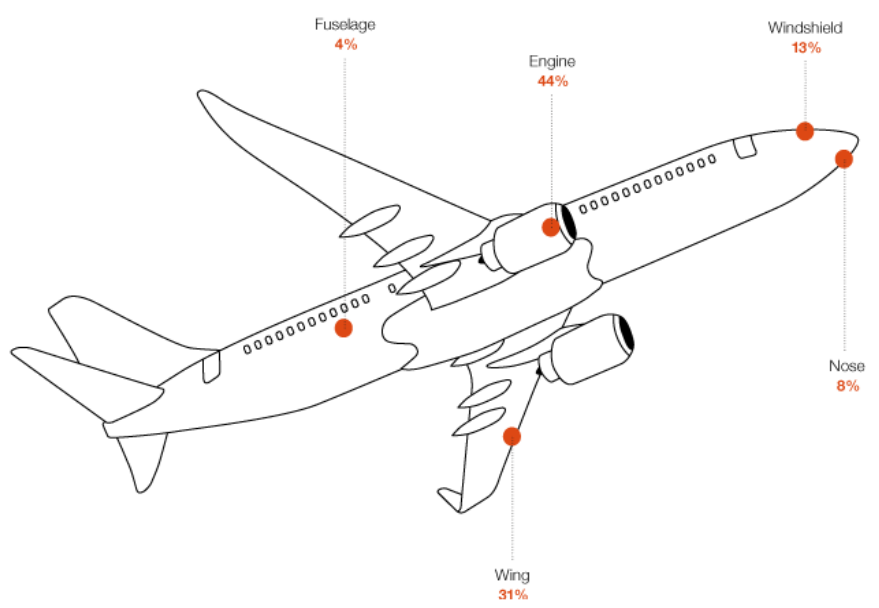

Fig 4. Locations of bird-strike damage [13]

To avoid these damages the ideology we have used, helps play a regular role. As mentioned by a writing, consistency of the device and exertions is a vital and major needed talent to realize the task.

A novel approach was hence developed using the ultrasonic radiations which will be radiated using piezo speakers during the Take-Off and Landing. 


\section{Birds and Ultrasound}

There are few arguments related to birds hearing ultrasound. In 1960 it was proposed that birds could not hear ultrasound. Bird-X and Dr. Philip Whitford have proved that birds are sensitive to ultrasound.

Dr. Whitford observes a goose's response to ultrasound in a lab setting, before he stopped the experiment, due to the distress clearly experienced by the goose.

He tried experimenting with geese and a very high-tech ultrasound generating device from a university. He brought a goose into the sound lab in a large dog crate and tested it with a burst of 22,000 cs $(\mathrm{Hz})$ sound. The bird toppled over instantly and became a rigid mass of flesh. Only the eyelids flickered open and closed. Within a minute of the time the sound stopped, the goose recovered and stood, seemingly unharmed. He repeated the test several more times with the same results. He only speculated based on outward appearances that at that distance and intensity, the ultrasound may have affected molecular level channels of nerves and muscle cells. Whatever it was, it was a striking response to the sound [22]. This article gives a clear explanation of bird behavior when they come across ultrasonic waves.

\section{Design of the Device}

The device consists of the PIC 18 microcontroller which is the important unit that generates the respective frequencies followed by piezo ultrasonic speaker to radiate them.

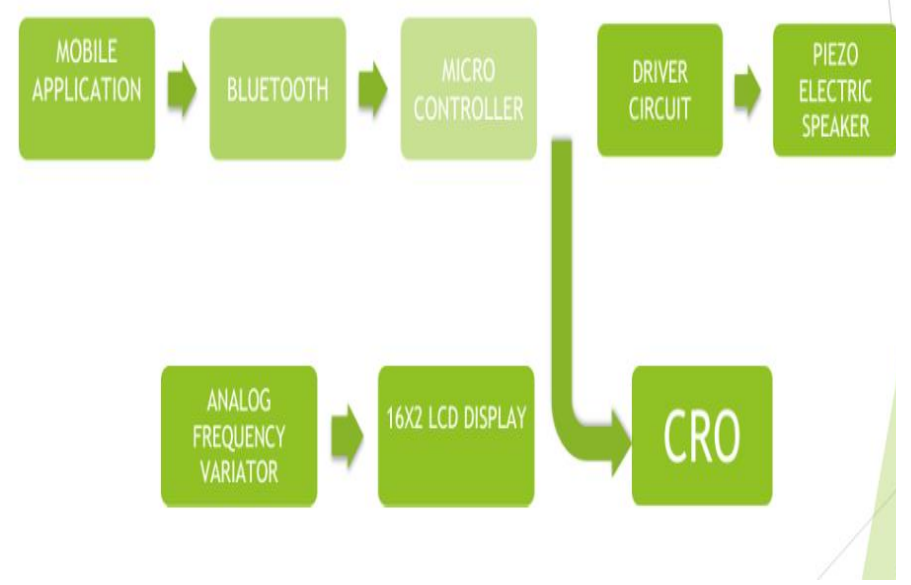

Fig 5. Block Diagram of the repelling device

When the aircraft begins to ascend or descend a manual switch is turned on (present on-board the aircraft) to start the ultrasonic radiations to the preferred range.
Fig 5 shows the block diagram of the upcoming device designed by us and the role of each component will be explained in the next context.

The working of the device follows the following steps:

i. Frequency generation

ii. Radiating the sound (generated frequency)

The two step implementation has been explained in detail in next section. Prior to knowing the complete detail of the implementation, a flowchart in Fig 6 shows a brief description of working of the device.

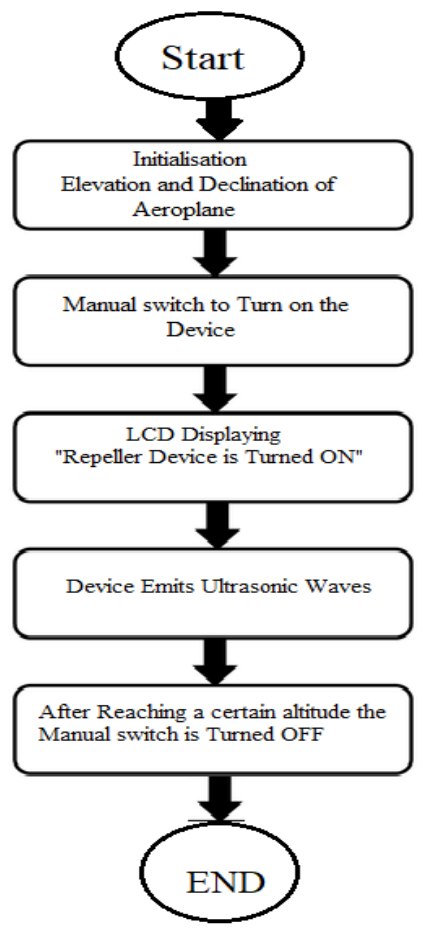

Fig 6: Flowchart of the repelling device to be implemented

\section{Generation of Frequency and Varying the Frequency}

The ultrasonic frequency ranges from $15 \mathrm{Khz}$ to $30 \mathrm{Khz}$. This frequency range must be genarated for the device. Frequency genaration is performed by a microcontrollerPIC 18F46k22. Frequency is generated by the Pulse Width Modulation technique (PWM). PWM is the method to produce variable voltages using digital means i.e. converting digital to pulsating signals. PWM is usually used to control speed of motors by varying voltage supplied to it and also used to as a modulation scheme to encode message into pulsing signal for transmission. A flowchart representing the frequency generation is depicted in Fig 7.

Pulse Width Modulation (PWM) is a digital signal which is most commonly used in control circuitry. This signal is 
set high (5v) and low (0v) in a predefined time and speed. The time during which the signal stays high is called the "On time" and the time during which the signal stays low is called the "Off time". Microcontroller generates frequency using the information regarding the PWM frequency (period) and the duty cycle which is given externally. Period refers to the Total time duration of the signal and duty cycle is the amount of time the signal is high or in the $\mathrm{ON}$ state. The percentage duty cycle describes the percentage of time the digital signal is $\mathrm{ON}$ over an interval of time. Hence the microcontroller generates the frequency provided through the app which is interfaced via a Bluetooth explained in coming section of 'Digital Method', depending on the duty cycle provided.

According to a survey different birds have reacted to different frequencies [6].

We propose two techniques to vary the frequency:

i. Analog Technique

ii. Digital Technique

Analog Method: This technique is a simple method of using push buttons that are used for increasing or decreasing the frequency by one step and displaying the frequency on an LCD. This is performed by making a connection to the microcontroller and an LCD display to display the frequency.

To verify this frequency a CRO will be used to monitor the exact frequency level.

A disadvantage of this technique is that it can only vary the frequency to quantum number of units (i.e. 1,2,3...) and does not help with decimal variations.

Digital Method: To overcome the disadvantage of analog method a digital method is used. This is performed by a developing an 'application' or an APP for varying the frequency.

A mobile application is developed for varying the frequencies with decimal variation. This application is interfaced through a Bluetooth to the microcontroller.

This application will be installed in a smart device (like smart phones) and interfaced with microcontroller using a Bluetooth.

APP interfacing with the microcontroller via a Bluetooth. The app contains three different ways to select the PWM frequency and the duty cycle. These are: Sliding method, Drop-down and manual selection as shown in the Fig 6.

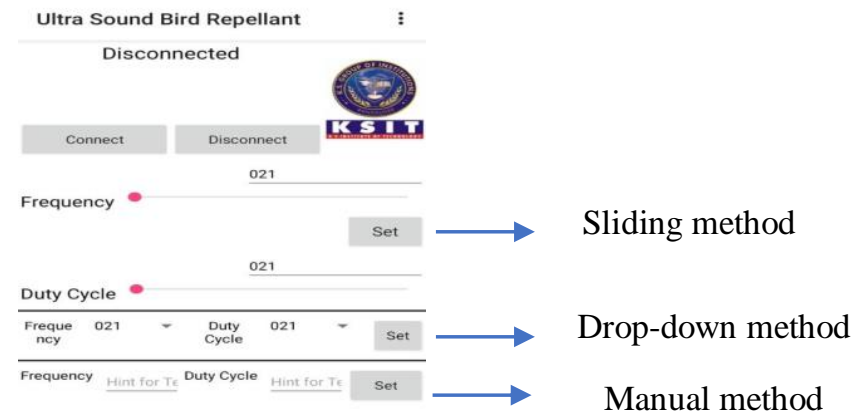

Fig 6. Application developed to select the frequency and duty cycle

HC-05 is a Bluetooth device used for wireless communication. It works on serial communication (USART). It is a 6-pin module. The device can be used in 2 modes; data mode and command mode.

The data mode is used for data transfer between devices whereas command mode is used for changing the settings of the Bluetooth module. AT commands are required in command mode. The module works on $5 \mathrm{~V}$ or $3.3 \mathrm{~V}$. it's an on board $5 \mathrm{~V}$ to three. $3 \mathrm{~V}$ regulator.

As HC-05 Bluetooth module has $3.3 \mathrm{~V}$ level for Receiving/Transmitting and microcontroller can detect 3.3 V level, so, no must shift transmit level of HC-05 module. But we'd choose to shift the transmit voltage level from microcontroller to RX of HC-05 module. 


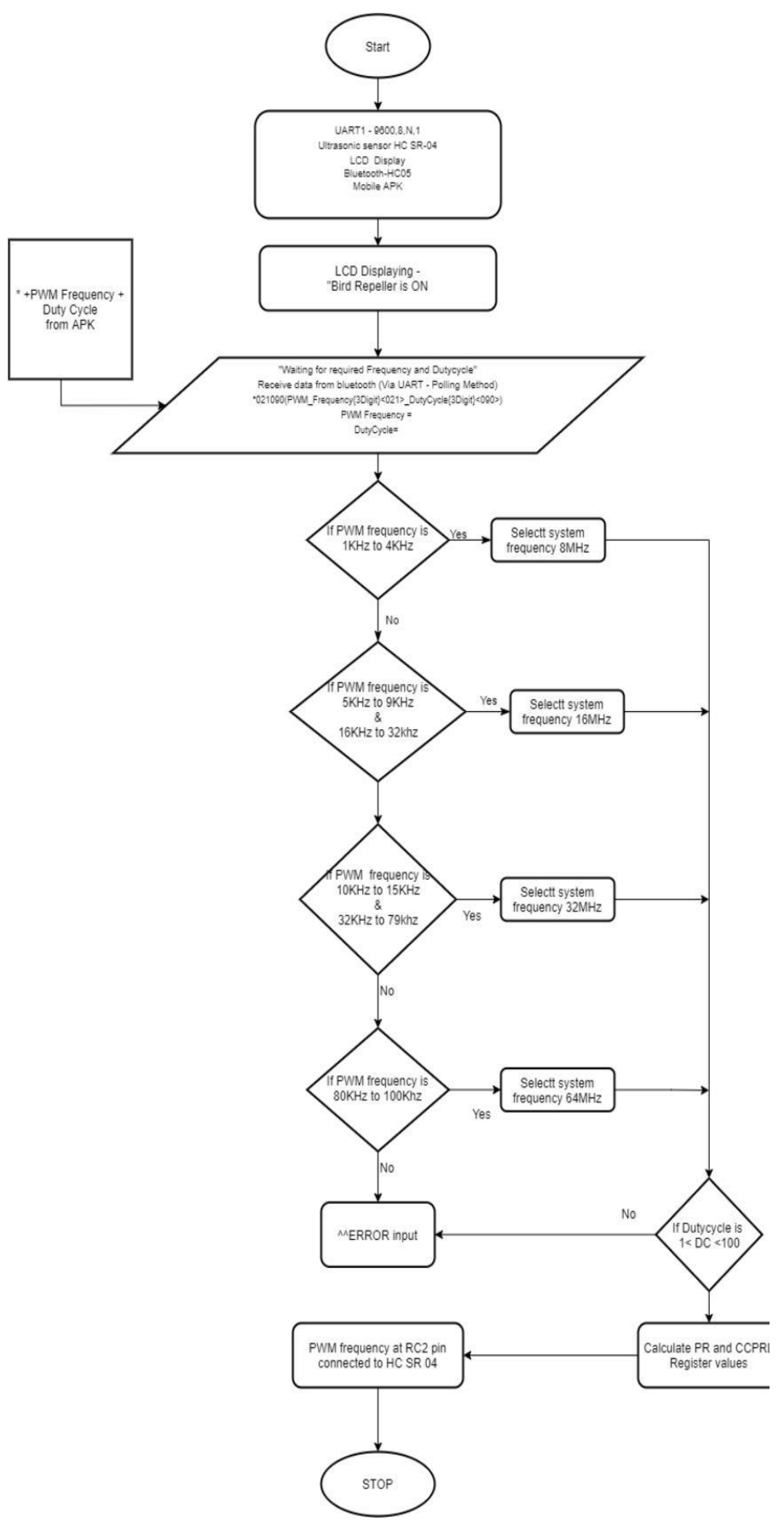

Fig 7 Flowchart depicting generation of frequency by PIC 18

\section{Radiating the generated sound (Frequency)}

Once the frequencies are generated it must be dispersed. Ultrasonic frequencies are radiated using Piezo-electric transducer. The piezo speaker working has been explained within the below context. The piezo effect occurs through compression of a piezoelectric material or
Piezoceramic material. For piezoelectricity to be generated, it needs that material to be compressed or squeezed. Mechanical stress applied to piezoelectric ceramic material generates electricity. As shown in Fig 8 , the 2 metal plates sandwich the piezo crystal. The metal plates collect the fees, which creates/produces voltage (lightning bolt symbol), i.e., piezoelectricity. during this way, the piezo effect acts sort of a miniature battery, because it produces electricity [23].

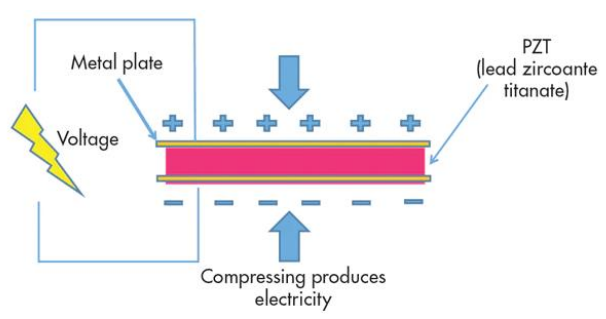

Fig 8. Direct Piezo electric effect

The piezo effect will be reversed, which is noted because the inverse electricity. this is often created by applying electrical voltage to create a crystal shrink or expand as shown in fig 9. The inverse piezo effect converts electricity to energy. Using the inverse piezoelectricity can help develop devices that generate and produce acoustic sound waves [23].

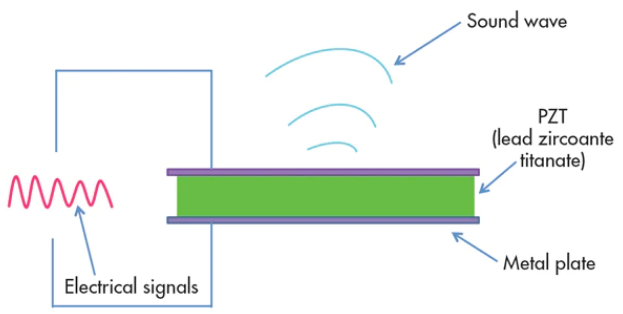

Fig 9. Indirect Piezo electric effect

The piezo speaker is driven by a driving circuit from the microcontroller for its working. The Piezoelectric speaker is thought by quite an few names, piezo, buzzer and crystal loudspeaker are some of them. In its essence, it's a speaker that uses a piezoelectricity to come up with the sound. By applying a voltage to a piezoelectric material, it creates the initial mechanical motion. Furthermore, diaphragms and resonators typically convert the motion into audible sound. Piezoelectric speakers are relatively easy to drive compared to other speaker's design. In ultrasound applications, piezoelectric speakers operate well within the range of $1-5 \mathrm{kHz}$ and up to $100 \mathrm{kHz}$ [24]. Applying an electrical field to a crystal results in the addition or removal of electrons, and this successively causes the 
crystal to deform and thereby generate alittle physical force. the electrical field established within the piezoelectric material by a possible difference applied across a piezo speaker propagates effectively instantly, which suggests that the whole material experiences an immediate force and begins to flex immediately [24].

Hence applying a possible difference across the terminals of a piezoelectric speaker will cause it to maneuver and make sound.

Piezoelectric speakers operate by the converse piezo effect which was described within the earlier section. Applying an alternating voltage, like a square wave, will cause the fabric to vibrate and build a sound. a continuing voltage won't produce a sound. This alternating voltage is produced by the PWM generated output with an appropriate duty cycle (i.e. Approximately 50\%). These alternating signals energizes the speaker to provide sound which is able to be driven by an enclosed driving circuit.

\section{Stages of Working of the Device}

Stage 1: Device to be turned on during Take-Off or landing

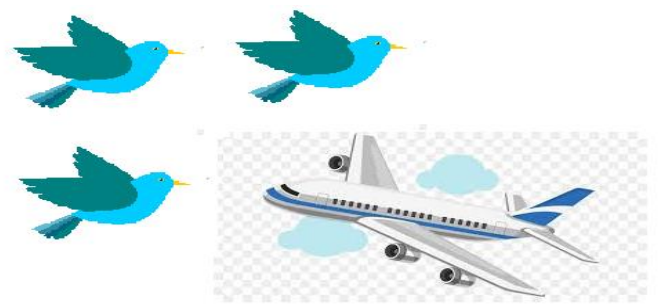

Stage 2: Generation of ultrasonic waves

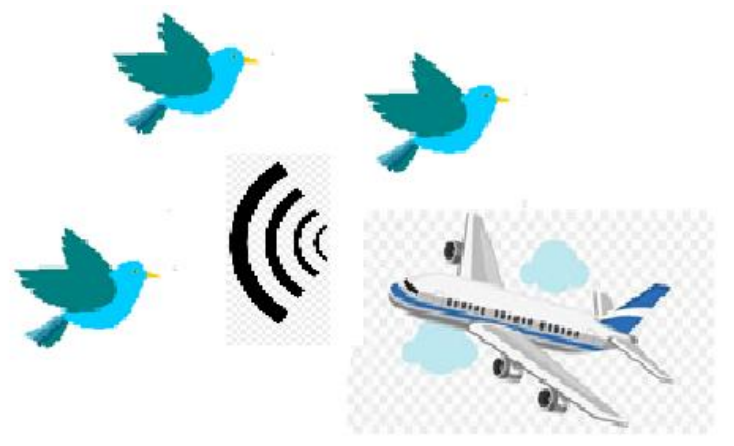

Stage 3: Repelling of Birds

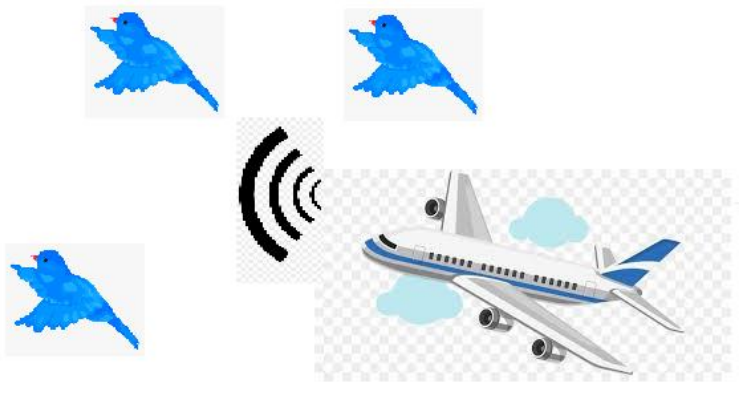

During a flight's Take-Off its engines are designed to move it forward and at a high speed. This makes a rapid air-flow over the wings, which throw the air downwards i.e. towards the ground generating an upward force called 'lift'. This entire process of Take-Off takes an average of 30-35 seconds. It is during this period of time when the flight is at an altitude of 500 feet from the ground terrain which is an average flying height of birds. Hence TakeOff of a flight is the period where Bird Strikes are very often.

To control this situation a device must be placed at regions of the flight where Bird Strikes are more often (such as Jet Engine, wing Leading Edge and many more). A switch on-board connected to the device must be turned On and the device with enormous power should avoid and control the birds nearing the aero plane.

This device must be equipped with ultrasonic radiations. When birds come across Ultrasonic radiations, they become disoriented or irritated by the noise according to a research.

\section{RESULTS}

Pigeons are a unit one in all the foremost perturbing birds in numerous areas. We tend to predict effective results once experimenting with the pigeons that may provide aerodromes a productive resolution to avoid Bird Strikes. The pigeons got repelled at a frequency of $37 \mathrm{Khz}$ and a small variation in the frequency between $35-37 \mathrm{Khz}$ causes variation in the bird. The below figure is the device built by us. 


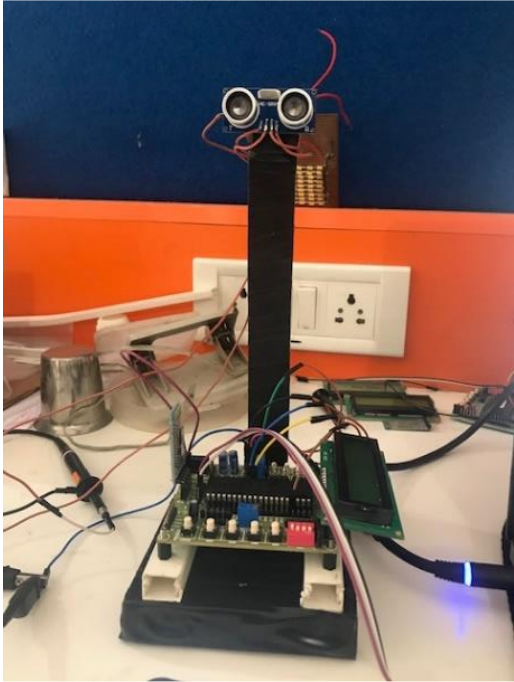

Fig 8. The implemented device

\section{CONCLUSION}

The above proposed method will be effective with proper delivery of frequencies to be generated. For real-time purpose (i.e. device on the aircraft) must radiate these frequencies with enormous power for effective results.

\section{ACKNOWLEDGMENT}

This research was completely supported by our college, Kammavari Sangha Institute of Technology, Bangalore under the guidance of Mr. Santosh Kumar B.R, Associate Professor, ECE Department, KSIT.

\section{REFERENCES}

[1] S. M. Satheesan,1999, "Zero bird-strike rate - an achievable target, not a pipedream", University of Nebraska, Lincoln, Bird Strike Committee Proceedings.

[2] S. Aravind, B. Ganesh, R. Mousia, S. Vignesh, October, 2014, "Optimization of Bird Hazard Reduction in Coimbatore International Airport", Krishi Sanskriti Publications, Vol 1, No 5.

[3] Zdobyslaw Goraj, Kamila Kustron, April 2018 "Review of Current Research Trends in Bird Strike and Hail Impact Simulations on Wing Leading Edge", Article in Aircraft Engineering and Aerospace Technology. https://www.researchgate.net/publication/324189256_Re view_of_current_research_trends_in_bird_strike_and_ha il_impact_simulations_on_wing_leading_edge

[4] Isabel C. Metz, Joost Ellerbroek, Thorsten Mühlhausen, Dirk Kügler, Jacco M. Hoekstra, 13 March
2020“The Bird Strike Challenge”, MDPI, received: 13 February 2020; Accepted: 9 March 2020;

[5] Jaiye Jehoshaphat Dukiya, Vimal Gahlot, 25 October 2012 "An Evaluation of Bird Strikes on Flight Safety Operations at International Airports".

[6] Fuliang Le, Jiawei Luo, Gongping Wu, 2009, "An Uninterrupted Bird Repeller on Transmission Line", Proceedings of the 2009 IEEE International Conference on Robotics and Biomimetics, China.

[7] Yahot Siahaan, Bheta Agus Wardijono and Yulisdin Mukhlis,2017 "Design of Birds Detector and Repellent Using Frequency Based Arduino Uno with Android System".

[8] Navinesshani Permal, Thiviya Barathi Raja Segaran, Renuga Verayiah, Farrukh Hafiz Nagi, Agileswari K. Ramasamy,2019 "Hardware Implementation of Beam Formed Ultrasonic Bird Deterrent System", IEEE 4th International Conference on Computer and Communication Systems.

[9] V. Arun pandiyan, J. Murugan Senthamilan, D. Uday Kumar, V. Vinithkumar, March 2019 "Fabrication of Mobile Ultrasonic Bird Repeller" International Journal of Innovative Research in Advanced Engineering (IJIRAE) Issue 03, Volume 6.

[10]https://www.boeing.com/commercial/aerom gazine/articles/2011_q3/4

[11]https://lasmentirasdebarajas.blogspot.com/2012_05_ 25_archive.html

[12]https://www.skybrary.aero/index.php/Bird_Strike

[13] https://en.m.wikipedia.org/wiki/Bird_scare

[14]https://en.wikipedia.org/wiki/Phased_array_ultrasoni cs

[15]https://www.sciencedirect.com/topics/nursing-andhealth-professions/transducer

[16]https://www.boeing.com/commercial/aerom gazine/articles/2011_q3/4

[17]https://indianexpress.com/article/business/aviation/a hmedabad-leads-among-major-airports-in-wildlifestrikes-11-cases-for-every-10000-flights-6274972

[18] https://en.wikipedia.org/wiki/Bird_strike 
[19]https://www.ainonline.com/aviation-news/2013-0614/india-buys-bird-strike-radars

[20]https://blog.klm.com/7-remarkable-facts-about-jetengines/

[21]http://flightdotcom.blogspot.com/2012/04/birdstrike-avoidance-duringtakeoff.html

[22]https://www.birdx.com/filebin/pdf/research/Ultrasou nd_Whitford Study_observaions.pdf

[23] https://www.electronicdesign.com/powermanagement/article/21801833/what-is-the-piezoelectric-

effect

[24]https://www.allaboutcircuits.com/technicalarticles/how-piezoelectric-speakers-work/

[25]http://ww1.microchip.com/downloads/en/DeviceDoc /40001412G.pdf

[26]https://microchipdeveloper.com/dtda:icspconsiderations

[27]https://lastminuteengineers.com/arduino-sr04ultrasonic-sensor-tutorial/

[28]https://components101.com/ultrasonic-sensorworking-pinout-datasheet

[29]https://components101.com/wireless/hc-05bluetooth-module

[30]https://components101.com/16x2-lcd-pinoutdatasheet

[32] https://patents.justia.com/patent/10045525

https://www.hindustantimes.com/india-news/casesinvolving-stray-animals-bird-hit-rise-over-fiveyears/story 